\title{
ADVERSE DRUG REACTION MONITORING AMONG HYPERTENSIVE PATIENTS OF TERTIARY CARE CENTER OF NORTH INDIA RELATED TO ANTIHYPERTENSIVE DRUGS
}

\author{
SEEMA MISHRA ${ }^{1 *}$, SYED S AHMAD ${ }^{1}$, NILAM NIGAM ${ }^{1}$, PRATAP SHANKAR ${ }^{2}$, SHRAVAN KUMAR ${ }^{3}$, VINAY KUMAR ${ }^{1}$ \\ SHALINI GUPTA ${ }^{1}$
}

${ }^{1}$ Department of Pharmacology, Rama Medical College Hospital and Research Centre, Kanpur, Uttar Pradesh, India. ${ }^{2}$ Center For Advance Research, King George's Medical University, Lucknow, Uttar Pradesh, India. ${ }^{3}$ Department of Medicine, Rama Medical College Hospital and Research Centre, Kanpur, Uttar Pradesh, India. Email: drseemamdixit@gmail.com

Received: 14 December 2020, Revised and Accepted: 22 January 2021

ABSTRACT

Objective: The objective of the study was to monitor the adverse drug reactions (A.D.Rs.) associated with antihypertensive drugs.

Methods: All patients coming to the department with blood pressure systolic above $120 \mathrm{mmHg}$ and diastolic above 90 mmHg and prescribed hypertensives will be screened for the study.

Results and Discussion: A total of 136 patients were observed during the study. Out of 136 patients, 23 (17\%) A.D.Rs. were recorded. A study conducted by Ramesh et al. in the Indian capital reports that $22.3 \%$ of the patients experienced A.D.Rs.

Conclusion: Furthermore, any appearance of A.D.Rs. due to side effects of the drugs or due to bad control and patients non-compliance, it was treated mainly by decreasing the doses of the drugs, switching them to another active substance from the same pharmacological group, or by adding more active substances from different pharmacological groups in lower dosages to achieve the B.P goals.

Keywords: Adverse drug reaction, Monitoring, Hypertensive patients, Tertiary care center, India, Antihypertensive drugs.

(C) 2021 The Authors. Published by Innovare Academic Sciences Pvt Ltd. This is an open access article under the CC BY license (http://creativecommons.org/ licenses/by/4.0/) DOI: http://dx.doi.org/10.22159/ajpcr.2021v14i3.40496. Journal homepage: https://innovareacademics.in/journals/index.php/ajpcr

\section{INTRODUCTION}

With the advent of newer medicines and evolution of the science, the numbers of treatment options for a single disease have increased. Therefore, every drug in the therapeutic area poses both benefits and potential threat for causing severe side effects. At times, these side effects are preventable and a timely reporting of same can avoid unwanted health hazards and save millions of lives. An initiative made in the same direction was to design and implement adverse event reporting systems by individual nations and then was adopted by the whole world either unanimously with global organizations or individualizing their own reporting system. Pharmacovigilance is entirely about monitoring adverse drug reactions (A.D.Rs.) and hence was defined as "The detection in the community of drug effects, usually adverse" [1].

Hypertension is a global public health issue. It is an important public health concern because of its associated morbidity, mortality, and economic impact on the society. Overall prevalence of hypertension in India reported 29.8\% [2]. Nearly 1 billion people have high blood pressure (hypertension) globally; out of these, developing countries having two-thirds of patients. Premature deaths worldwide are mostly caused by hypertension and the disease is spontaneously growing with the estimation of 1.56 billion adults will be living with hypertension in 2025 [3]. India also facing substantial public health burden on cardiovascular health and health-care systems [4-6]. Approximately $57 \%$ of all stroke deaths and $24 \%$ of all coronary heart disease deaths in India are directly by hypertension. Even the WHO also rates hypertension as one of the most important causes of premature deaths worldwide [5-10]. The present study is conducted to monitor the A.D.Rs. associated with antihypertensive drugs.

\section{METHODS}

All patients coming to the department with blood pressure systolic above $120 \mathrm{mmHg}$ and diastolic above $90 \mathrm{mmHg}$ and prescribed hypertensives will be screened for the study. Those who satisfy the inclusion criteria will be enrolled after taking written informed consent. Diagnosed patients of hypertension above the age of 18 years, and diagnosed with primary hypertension, will be included in the study.

The various study tools that will be used are the suspected ADR reporting form issued by Central Drugs Standard Control Organization under Pharmacovigilance Programme of India which will record all the information, such as name, age, sex, weight, other relevant history including pre-existing medical conditions, details of suspected ADRs, and details of suspected medications that the patients might be taking. A.D.Rs. reporting form records all the essential information regarding the adverse effects: The onset and severity of the A.D.R. experienced, the impact of A.D.Rs. on the treatment and work capacity of the patient, the $\operatorname{drug}(\mathrm{s})$ involved, the date of starting the suspected drugs, and the date of reporting of the A.D.Rs. Causality assessment will be done using Naranjo's causality assessment scale [11].

Data management and analysis

Data will be aggregated according to disease profile and other relevant information required for the study. Causality assessment was done using Naranjo's causality assessment scale.

For patients on antihypertensive treatment Inclusion criteria

The following criteria were included in the study:

- Newly diagnosed patients of hypertension with blood pressure above $120 / 90 \mathrm{~mm} \mathrm{Hg}$ 
- Patients with age more than 18 years

- Patients of either sex

- Patients having baseline (pre-treatment) biochemical parameters other than blood sugar (i.e., liver function test and kidney function test) within normal range

- Patients having no associated comorbidities

\section{Exclusion criteria}

The following criteria were excluded from the study:

- Patients who were unwilling to participate and did not give consent in the study

- Patients who were unable to give interview

- Patients with incomplete medical records

- Patients with chronic liver disease such as cirrhosis, chronic hepatitis, and acute viral hepatitis

- Terminally ill patients

- Patients with concurrent major psychiatric illness and/or concurrent major medical illnesses.

Naranjo's causality assessment scale

The Naranjo's criteria classify the probability that an adverse event is related to drug therapy based on a list of weighted questions, which examine factors such as the temporal association of drug administration and event occurrence, alternative causes for the event, drug levels, dose-response relationships, and previous patient experience with the medication.

The A.D.Rs. are assigned to a probability category from the total score as follows:

Definite if the overall score is 9 or greater, probable for a score of 5-8, possible for $1-4$, and doubtful if the score is 0 .

The Naranjo's criteria do not take into account drug-drug interactions. Drugs are evaluated individually for causality, and points deducted if another factor may have resulted in the adverse event, thereby weakening the causal association.

\section{Statistical analysis}

Categorical variables will be presented in number and percentage (\%). Qualitative variables will be compared using Chi-square test/Fisher's exact test as appropriate. $\mathrm{p}<0.05$ will be considered statistically significant. Statistical analysis was performed using GraphPad QuickCalcs software available online at http://graphpad.com/ quickcalcs/. The data will be entered into MS EXCEL spreadsheet and analysis will be done using Statistical Package for the Social Sciences (SPSS) version 21.0.

\section{RESULTS}

The present study was an open and non-comparative, based on a questionnaire (A.D.R. monitoring form) drafted according to Naranjo's A.D.R. monitoring guidelines, which included data relating to patient demographic details (age, sex, height, weight, and body mass index [BMI]), medical history, present drug treatment, description, assessment, and treatment of A.D.Rs. The study protocol was approved by Institutional Medical Ethics Committee, Rama Medical College and Research Centre, Kanpur, U.P. The present study was conducted between June 01, 2018 and November 30, 2018 by attending the medicine OPD on a daily basis. A total of 23 A.D.Rs. were observed in 136 patients during the study.

\section{A.D.R. monitoring of antihypertensive medication}

Twenty-three A.D.Rs. were observed in 136 patients of mean age $49.6 \pm 12$ years; mean BMI $25.7 \pm 8.1 \mathrm{~kg} / \mathrm{m}^{2}$. A higher percentage of A.D.Rs. occurred in males (52\%). A total of 7 (31.8\%) were observed in the patient age group of 41-50 years, followed by $6(27.2 \%)$ in 31-40 years, $5(22.7 \%)$ in 51-60 years, and 2 and 3 A.D.Rs. in each of $61-70$ years and $>70$ years age groups.
Only two A.D.Rs. were observed in hypertensive patients suffering from concomitant disease (one each with diabetes mellitus and asthma). Combination therapy was associated with significantly high occurrence $(p<0.05)$ of A.D.Rs., with a total of $16(69.7 \%)$ as compared to monotherapy $(n=7,30.43 \%)$.

Furthermore, most patients had an experience of ADRs due to pharmacotherapy. More specific $72 \%$ of study population had an experience of one A.D.R., $18 \%$ had an experience of two A.D.Rs., and only $8 \%$ had experience of three A.D.Rs. (Fig. 1).

On the causality scale of Naranjo's, 7 (30\%) A.D.Rs. were classified probable, 13 (56\%) possible, 1 (4.3\%) definite, and 2 (13\%) doubtful (Fig. 2).

In our study, we found that calcium channel blockers (CCBs) are the most common groups of drugs to treat the hypertensive patients, then followed by beta-blockers and diuretics. CCBs accounted for $34.78 \%$ of total A.D.Rs. followed by beta-blockers (26.08\%), angiotensinconverting enzyme (ACE) inhibitors $(17.39 \%)$, angiotensin receptor blockers (ARBs) (8.69\%), and diuretics (4.3\%).

Among individual drugs, amlodipine was the drug associated with maximum A.D.Rs., including pedal edema, general edema, giddiness, headache, and abdominal pain. Beta-blockers, namely, atenolol, metoprolol, and nebivolol were the next which reported A.D.Rs. such as hypotension, headache, impotence, and bronchospasm. ACE inhibitors and ARBs were associated with dry cough, taste alteration. Patients on diuretics reported least number of A.D.Rs. (Table 1). Furthermore, 5\% of patients with other concomitant disease like dyslipidemia showed myalgia and increased CPK levels due to statins which was an additive to antihypertensive therapy, and the rest of A.D.Rs., each of them accounts $1 \%$ or less of the total study population.

The A.D.Rs. associated with central nervous system were found to be most frequent in our study followed by cardiovascular A.D.Rs.,

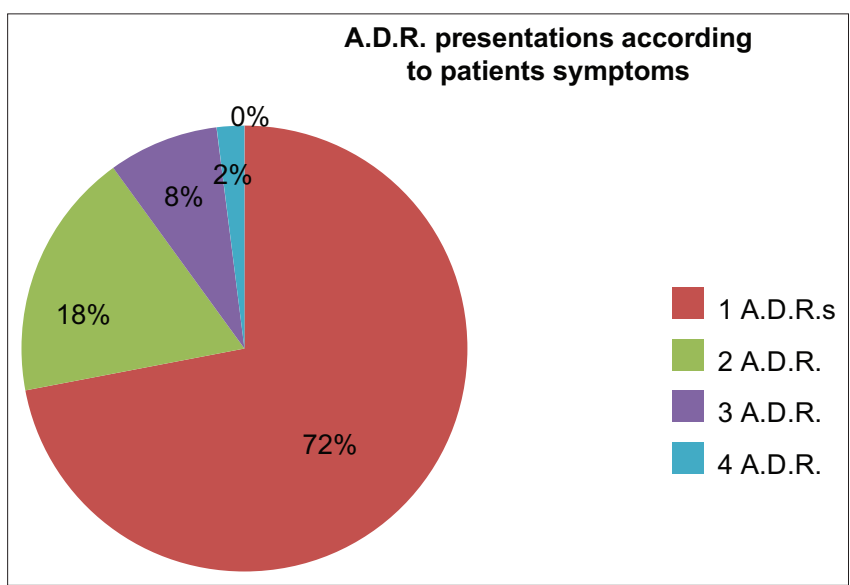

Fig. 1: The pie graph shows \% frequency of adverse drug reaction (A.D.R.) reported per person where $100 \%$ is the total number of patients on antihypertensive who experienced A.D.Rs

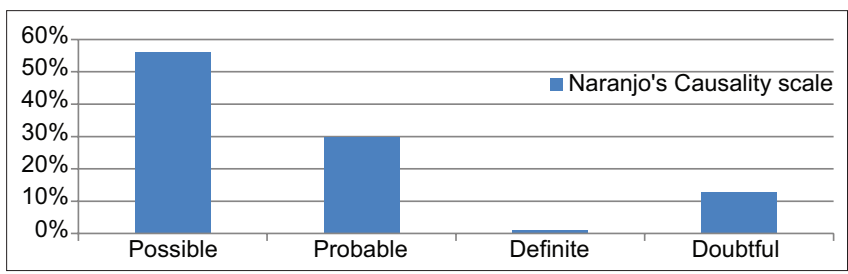

Fig. 2: The bar graph shows \% of adverse drug reaction classified as possible, probable, unlikely and unclassified according to Naranjo's causality criteria $(n=23)$ 
Table 1: \% of A.D.R. experienced by patients receiving respective classes of antihypertensive drugs and other concomitant drugs if any (figure in bracket denotes the total number of episodes reported due to a particular class of drug)

\begin{tabular}{|c|c|c|c|c|}
\hline \multicolumn{5}{|c|}{ Therapeutics class of suspected antihypertensive medications and adverse drug reactions. } \\
\hline $\begin{array}{l}\text { Therapeutic class of } \\
\text { drug }\end{array}$ & Drugs & Suspected A.D.R. & $\begin{array}{l}\text { Total number of patients with A.D.R. } \\
\text { (No. of patients receiving the drug) }\end{array}$ & Percentage of A.D.R. \\
\hline Calcium channel blockers & Amlodipine & $\begin{array}{l}\text { Pedal edema (3) } \\
\text { General edema (2) } \\
\text { Giddiness (1) } \\
\text { Headache (1) } \\
\text { Abdominal pain (1) }\end{array}$ & 8 & $34.78 \%$ \\
\hline Beta-blockers & $\begin{array}{l}\text { Atenolol } \\
\text { Metoprolol } \\
\text { Nebivolol }\end{array}$ & $\begin{array}{l}\text { Hypotension (2) } \\
\text { Headache (1) } \\
\text { Xerostomia (1) } \\
\text { Bronchospasm (1) } \\
\text { Pedal edema (1) }\end{array}$ & 7 & $26.08 \%$ \\
\hline ACEIs & Enalapril & $\begin{array}{l}\text { Dry cough (2) } \\
\text { Xerostomia (1) } \\
\text { Taste alteration (1) }\end{array}$ & 4 & $17.39 \%$ \\
\hline ARBs & $\begin{array}{l}\text { Losartan } \\
\text { Telmisartan } \\
\text { Olmesartan }\end{array}$ & $\begin{array}{l}\text { Edema (1) } \\
\text { Headache (1) }\end{array}$ & 2 & $8.69 \%$ \\
\hline Diuretics & $\begin{array}{l}\text { Frusemide } \\
\text { Spironolactone }\end{array}$ & Hypotension (1) & 1 & $4.3 \%$ \\
\hline \multicolumn{5}{|c|}{ A.D.Rs. due to concomitant drugs } \\
\hline Statins & $\begin{array}{l}\text { Atorvastatin } \\
\text { Pravastatin } \\
\text { Rosuvastatin }\end{array}$ & $\begin{array}{l}\text { Pain in upper } \\
\text { abdomen (1) } \\
\text { vomiting (1) }\end{array}$ & 2 & \\
\hline $\begin{array}{l}\text { Other vitamin preparation } \\
\text { or antioxidant }\end{array}$ & $\begin{array}{l}\text { Omega } 3 \text { fatty } \\
\text { acid preparations }\end{array}$ & $\begin{array}{l}\text { Gastrointestinal } \\
\text { disturbances (1) }\end{array}$ & 1 & \\
\hline Analgesics & Aceclofenac & Swelling of face (1) & 1 & \\
\hline Drugs for LVF treatment & Digoxin & $\begin{array}{l}\text { Nausea (1) } \\
\text { Diarrhea (1) }\end{array}$ & 2 & \\
\hline $\begin{array}{l}\text { Hypoglycemic } \\
\text { medications }\end{array}$ & \multicolumn{4}{|c|}{ A.D.Rs. mentioned in the second section of the study } \\
\hline
\end{tabular}

A.D.R.: Adverse drug reaction, ARBs: Angiotensin receptor blockers, ACEI: Angiotensin-converting enzyme inhibitor

gastrointestinal A.D.Rs. (abdominal pain, constipation, and diarrhea), and respiratory system (Fig. 3).

The most common systems associated with A.D.Rs. in our study were the central nervous system, followed by cardiovascular system, gastrointestinal system, and respiratory and dermatological system (Fig. 4).

\section{DISCUSSION}

We studied 136 patients on antihypertensive medications and observed the incidence and pattern of ADRs in them. Out of 136 patients, $23(17 \%)$ A.D.Rs. were recorded. A study conducted by Ramesh et al. [12-15] in the Indian capital reports that $22.3 \%$ of the patients experienced A.D.Rs. Another report on A.D.R. monitoring in North India by Garg and Singhal [15] mentions that $5.9 \%$ of all visits to the medical department are drug related, and A.D.Rs. accounted for $45 \%$ of events which depicts a higher percentage of A.D.Rs.

According to the Naranjo's causality scale, 30\% (7) of cases were classified probable, $56 \%$ (13) of cases possible, $13 \%$ of cases were doubtful, and $4 \%$ of cases fell in the definite category. This result is similar to studies done by Khurshid $[15,16]$.

Out of 23 A.D.Rs. recorded in antihypertensive patients, $34.78 \%$ (8 out of 23) was observed in patients prescribed CCBs, $26.08 \%$ (7 out of 23) in patients prescribed on beta-blockers, $17.39 \%$ ( 4 out of 23 ) by ACE inhibitors, $8.69 \%$ ( 2 out of 23 ) by ARBs, and 1 out of 23 that is 4.35 by diuretics is responsible for causing A.D.R.

A.D.Rs. of particular drugs can influence compliance of antihypertensive agents, because they frequently decrease quality of life, which is

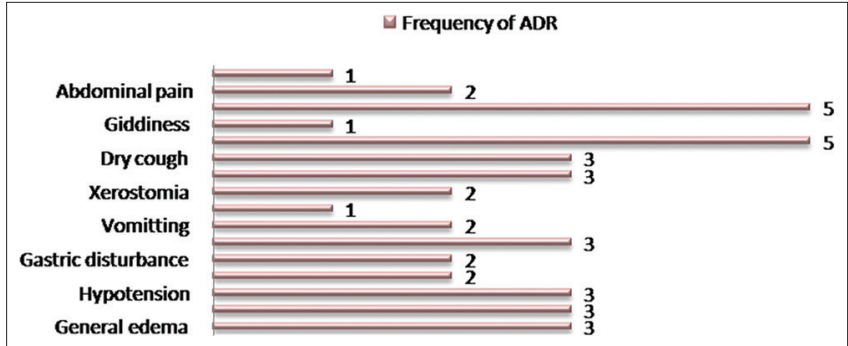

Fig. 3: The graph depicts symptom wise involvement of adverse drug reactions (A.D.Rs.) according to the frequency of category of A.D.R

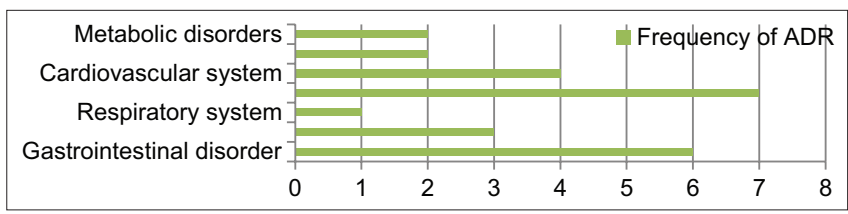

Fig. 4: The graph depicts system wise involvement of adverse drug reactions (A.D.Rs) according to the frequency of category of A.D.R

important by asymptomatic disease. Therefore, we were looking for physicians notice in health documentation regarding A.D.Rs.

Any appearance of A.D.Rs. due to side effects of the drugs or due to bad control and patient's non-compliance (refuse to follow doctors' instructions or forgetting to take the medicine), it was treated mainly by decreasing the doses of the drugs, switching them to another 
active substance from the same pharmacological group (depending on patients' tolerability), or by adding more active substances from different pharmacological groups in lower dosages and combined pills, to achieve the B.P. goals. Furthermore, in case of patients' noncompliance, the use of combined slow release regimens it was preferred.

Among the different A.D.Rs. reported from different systems due to antihypertensive medications, most of the A.D.Rs. were of central nervous system origin, followed by cardiovascular system, and gastrointestinal and respiratory system.

\section{CONCLUSION}

Out of 120 patients, 23 patients developed A.D.Rs. The age group 51-60 years being more vulnerable showed higher incidence and outnumbered the patients in other group who developed A.D.Rs. As compared to females, there were more males with A.D.Rs. because male constituted more of our sample population. Out of 23 A.D.Rs. recorded, percent A.D.R. frequency was seen maximum in patients prescribed CCBs that is $34.78 \%$. Maximum number of the patients developing A.D.Rs. came up with adverse effects related to central nervous system such as headache and giddiness. On assessment of causality through Naranjo's algorithm, maximum of the ADRs have been categorized under "possible" which is being followed by category of "probable" (56\%; 30\%). Furthermore, the most common comorbidities along with hypertension were dyslipidemia and C.H.D, as well as the most frequently used drug groups were anti-hyperlipidemic, BBs, anticoagulant-antiplatelet, and ARBs. More specific from the point of active substances atorvastatin, metoprolol, aspirin, and telmisartan in different combinations, doses, and dosage schemes seems to be the most favorable prescribed drugs.

Furthermore, any appearance of A.D.Rs. due to side effects of the drugs or due to bad control and patients non-compliance, it was treated mainly by decreasing the doses of the drugs, switching them to another active substance from the same pharmacological group, or by adding more active substances from different pharmacological groups in lower dosages to achieve the B.P. goals.

\section{AUTHORS' CONTRIBUTIONS}

All authors equally contributed in the study.

\section{CONFLICTS OF INTEREST}

None.

\section{AUTHORS' FUNDING}

Funding from the Department of Pharmacology, Rama Medical College Hospital and Research Centre, Kanpur, U.P., India-209217.

\section{REFERENCES}

1. Rawson NSB, Pearce GL, Inman WH. Prescription-event monitoring: Methodology and recent progress. J Clin Epidemiol 1990;43:509-22.

2. Anchala R, Kannuri NK, Pant H, Khan H, Franco OH, di Angelantonio E, et al. Hypertension in India: A systematic review and meta-analysis of prevalence, awareness, and control of hypertension. $\mathrm{J}$ Hypertens 2014;32:1170-7.

3. World Health Organization. Hypertension-Fact Sheet. Geneva: World Health Organization; 2018. Available from: http://www.searo.who. int/entity/noncommunicable_diseases/media/non_communicable_ diseases_hypertension_fs.pdf?ua $=1$.

4. Lim SS, Vos T, Flaxman AD, Danaei G, Shibuya K, Adair-Rohani H, et al. A comparative risk assessment of burden of disease and injury attributable to 67 risk factors and risk factor clusters in 21 regions, 1990-2010: A systematic analysis for the global burden of disease study 2010. Lancet 2012;380:2224-60.

5. Harikrishnan S, Leeder S, Huffman M, Jeemon P, Prabhakaran D. A Race against Time: The Challenge of Cardiovascular Diseases in Developing Economies. New Delhi, India: Centre for Chronic Disease Control; 2014.

6. Reddy KS, Shah B, Varghese C, Ramadoss A. Responding to the threat of chronic diseases in India. Lancet 2005;366:1744-9.

7. Gupta R. Trends in hypertension epidemiology in India. J Hum Hypertens 2004;18:73-8.

8. World Health Organization. The Atlas of Heart Disease and Stroke/ Judith Mackay and George Mensah; with Shanthi Mendis and Kurt Greenland. Geneva: World Health Organization; 2004. Available from: http://www.who.int/iris/handle/10665/43007.

9. Lopez AD, Mathers CD, Ezzati M, Jamison DT, Murray CJ. Global and regional burden of disease and risk factors, 2001: Systematic analysis of population health data. Lancet 2006;367:1747-57.

10. Kearney PM, Whelton M, Reynolds K, Muntner P, Whelton PK, He J. Global burden of hypertension: Analysis of worldwide data. Lancet 2005;365:217-23.

11. Naranjo CA. A method for estimating the probability of adverse drug reactions. Clin Pharmacol Ther 1981;30:239-45.

12. ALLHAT Officers and Coordinators for the ALLHAT Collaborative Research Group, The Antihypertensive and Lipid-Lowering Treatment to Prevent Heart Attack Trial. Major outcomes in high-risk hypertensive patients randomized to angiotensin-converting enzyme inhibitor or calcium channel blocker vs diuretic: The antihypertensive and lipidlowering treatment to prevent heart attack trial (ALLHAT). JAMA 2002;288:2981-97.

13. Mathers CD, Loncar D. Projections of global mortality and burden of disease from 2002 to 2030. PLoS Med 2006;3:e442.

14. Ramesh M, Pandit J, Parthasarathi G. Adverse drug reactions in a south Indian hospital-their severity and cost involved. Pharmacoepidemiol Drug Saf 2003; 12:687-92.

15. Garg KC, Singhal KC. Adverse reactions to propranolol, a non-selective beta-adrenergic blocking agent in hypertensive patients-a collaborative study. Indian J Physiol Pharmacol 1993;37:67-70.

16. Khurshid F. Monitoring of adverse drug reactions associated with antihypertensive medicines at a university teaching hospital in New Delhi. Daru 2012;20:34. 